\title{
Antenatal Ureaplasma urealyticum Respiratory Tract Infection Stimulates Proinflammatory, Profibrotic Responses in the Preterm Baboon Lung
}

\author{
ROSE M. VISCARDI, SERGEI P. ATAMAS, IRINA G. LUZINA, JEFFREY D. HASDAY, JU-REN HE, PATRICIA J. SIME, \\ JACQUELINE J. COALSON, AND BRADLEY A. YODER
}

\begin{abstract}
Departments of Pediatrics [R.M.V.] and Medicine [S.P.A., I.G.L., J.D.H., J.-R.H.], University of Maryland School of Medicine, Baltimore, MD 21201; Department of Medicine [P.J.S.], University of Rochester School of Medicine and Dentistry, Rochester, NY 14642; Department of Pathology [J.J.C., B.A.Y.], University of Texas Health Science Center; Department of Physiology and Medicine [B.A.Y.], Southwest Foundation for Biomedical Research, San Antonio, TX 78284
\end{abstract}

\begin{abstract}
Chronic inflammation and fibrosis are hallmarks of lung pathology of newborn Ureaplasma infection. We hypothesized that antenatally acquired Ureaplasma stimulates a chronic inflammatory, profibrotic immune response that contributes to lung injury, altered developmental signaling, and fibrosis. Lung specimens from 125-d gestation baboon newborns ventilated for $14 \mathrm{~d}$ that were either infected antenatally with Ureaplasma serovar 1 or noninfected, and 125-d and 140-d gestational controls were obtained from the Baboon BPD Resource Center (San Antonio, TX). Trichrome stain to assess fibrosis and immunohistochemistry for $\alpha$-smooth muscle actin $(\alpha$ SMA) and transforming growth factor $\beta_{1}\left(\mathrm{TGF} \beta_{1}\right)$ were performed. Lung homogenates were analyzed by enzyme-linked immunosorbent assay (ELISA) for cytokines [tumor necrosis factor $\alpha$ (TNF $\alpha)$, interleukin (IL)- $1 \beta$, TGF $\beta_{1}$, oncostatin M (OSM), IL-10, and interferon $\gamma(\operatorname{IFN} \gamma)$ ] and the chemokine MCP-1 and by Western blot for Smad2, Smad3, and Smad7. Compared with noninfected ventilated and gestational controls, Ureaplasma-infected lungs demonstrated more extensive fibrosis, increased $\alpha$-SMA and TGF $\beta_{1}$ immunostaining, and higher concentrations of active TGF $\beta_{1}$, IL- $1 \beta$, and OSM, but no difference in IL-10 levels. There was a trend toward higher Smad2/Smad7 and Smad3/Smad7 ratios in Ureaplasma lung homogenates, consistent with up-regulation of TGF $\beta_{1}$ signaling. Collectively, these data suggest that a prolonged proinflammatory response initiated by intrauterine Ureaplasma infection contributes to early fibrosis and altered developmental signaling in the immature lung. (Pediatr Res 60: 141-146, 2006)
\end{abstract}

$\mathrm{B}$ ronchopulmonary dysplasia (BPD) remains the major morbidity in infants born at less than $30 \mathrm{wk}$ of gestation (1). Although the pathogenesis of BPD is not completely understood, prolonged exposure of the immature lung during the saccular period of lung development to inflammation appears to play a critical role (1). Inflammation may be initiated in utero by intrauterine infection and augmented postnatally by ventilation and hyperoxia (1). Ureaplasma

Received January 11, 2006; accepted March 24, 2006.

Correspondence: Rose Marie Viscardi, M.D., University of Maryland Hospital, 22 S. Greene St., Room N5W68, Baltimore, MD 21201; e-mail: rviscard@umaryland.edu

B.A.Y.'s current affiliation is Division of Neonatology, The University of Utah School of Medicine, Salt Lake, UT 84158-1289.

Supported by National Institutes of Health Grants HL71113, HL52636, HL04492, HL075432, and P512RR13986.

DOI: 10.1203/01.pdr.0000228322.73777.05 parvum (serovars $1,3,6$, and 14) and $U$. urealyticum (UU) (serovars 2, 4, 5, and 7-13) are the most common organisms isolated from amniotic fluid and infected placentas (2). The presence of Ureaplasma as the only microbial isolate in the upper genital tract is significantly associated with adverse pregnancy outcomes, including premature delivery, histologic chorioamnionitis, neonatal morbidity, and perinatal death (2). Respiratory tract colonization has been associated with a higher incidence of neonatal pneumonia and BPD (3).

Recent human and experimental studies confirmed that exposure of the fetal and/or newborn lung to Ureaplasma contributes to altered lung development, persistent inflammation, and fibrosis. In a review of lung pathology of autopsy specimens from Ureaplasma-infected preterm infants, we observed moderate to severe fibrosis and increased numbers of alveolar macrophages and TNF $\alpha$ and TGF $\beta_{1}$-immunoreactive cells in all Ureaplasma-infected infants compared with gestational controls (GCs) and infants who died of pneumonia from other causes (4). Levels of IL- $1 \beta, \mathrm{TNF} \alpha$, and monocyte chemoattractant protein-1 (MCP-1) are elevated in tracheal aspirates from preterm infants with Ureaplasma respiratory colonization during the first weeks of life $(5,6)$. Intratracheal inoculation with Ureaplasma caused an acute bronchiolitis in 140-d preterm baboons (7) and an acute interstitial pneumonia in newborn (8) and juvenile mice (9). Similar findings were observed in the 125-d immature baboon model exposed to brief antenatal colonization with Ureaplasma (10). In these animals, there was confirmed vertical transmission and a persistent bronchiolitis and interstitial pneumonitis. Taken together, these findings indicate that Ureaplasma can elicit a persistent inflammatory response and cause significant disease in the preterm infant.

Abbreviations $\alpha$-SMA, $\alpha$-smooth muscle actin; BPD, bronchopulmonary dysplasia; GC, gestational control; MCP-1, monocyte chemoattractant protein-1; OSM, oncostatin M; UU, Ureaplasma urealyticum 
TGF $\beta_{1}$ ) has been implicated in lung morphogenesis, repair of lung injury, airway remodeling, and lung fibrosis (11). There is accumulating evidence that excessive TGF $\beta_{1}$ signaling during lung development contributes to alveolarization arrest and fibrosis, both hallmarks of BPD (11). TGF $\beta$ was detected at sites of lung injury in association with myofibroblast proliferation in lungs of infants dying of respiratory distress syndrome, implicating TGF $\beta$ in the preterm lung's response to injury (12). TGF $\beta_{1}$ is elevated in tracheal aspirates of infants who progress to BPD (13) and is increased in autopsy lung specimens from Ureaplasma-infected preterm infants (14). Overexpression of TGF $\beta_{1}$ in the newborn rodent lung produces a phenotype similar to human BPD with arrested lung sacculation, epithelial differentiation, and vascular development (15-17).

TGF $\beta$ signaling sequence involves ligand-receptor binding and activation, activated type I receptor interaction with and phosphorylation of Smad 2 and Smad3 proteins, and formation of hetero-oligomeric complexes of Smad2/3 and Smad4 that translocate to the cell nucleus and activate $\mathrm{TGF} \beta$-responsive gene transcription (18). Smad7 associates with the TGF $\beta$ type I receptor and provides negative feedback of TGF $\beta$ signaling by preventing Smad2/3 activation (19). The effect of Ureaplasma infection on the relative expression of the Smad proteins in the lungs of infants is unknown.

Epidemiologic and pathologic studies of human Ureaplasma infection have been hampered by multiple confounding factors, including variability in study populations, organism detection, and pathogenicity, and neonatal factors, such as mechanical ventilation, oxygen exposure, and postnatal infection. The 125-d immature baboon model manifests clinical and pathologic features similar to those of preterm infants at risk of BPD. To extend the initial observations of the antenatal Ureaplasma-colonized baboon model (10), we obtained archived lung specimens of these animals and controls from the Baboon BPD Resource Center (San Antonio, TX). In this study, we sought to investigate possible differences in collagen accumulation, myofibroblast distribution, TGF $\beta_{1}$ signaling, and the relative concentration of pro- and antiinflammatory cytokines/chemokines in the lungs of antenatal Ureaplasma-infected immature baboons compared with noninfected ventilated newborns and GCs. We hypothesized that Ureaplasma acquired in utero stimulates a chronic inflammatory, profibrotic immune response that contributes to lung injury, altered developmental signaling, and fibrosis.

\section{METHODS}

Introduction of intra-amniotic $U \boldsymbol{U}$ and animal management. All animal husbandry and handling and procedures were performed at the Baboon BPD Resource Center (San Antonio, TX) and approved by the Institutional Animal Care and Use Committee and conformed to American Association for Accreditation of Laboratory Animal Care guidelines. The details of these procedures are provided in the previous report (10). Briefly, 10 pregnant baboons (Papio papio) were inoculated at 122-123-d timed gestation in the intra-amniotic cavity with UU serovar subtype 1 in 10B broth (generously provided by G. H. Cassell, University of Alabama, Birmingham) at a concentration of $10^{7}$ colony-forming units (CFUs) followed by elective cesarean delivery at $125 \pm 2 \mathrm{~d}($ term $=185 \mathrm{~d})$. All newborns were intubated at birth, received a single bolus $(100 \mathrm{mg} / \mathrm{kg}$ ) of exogenous surfactant (Survanta, donated by Ross Laboratories, Columbus, $\mathrm{OH}$ ), and were ventilated with a pressure-limited, time-cycled infant ventilator (InfantStar, Infrasonics, San Diego, CA) for $14 \mathrm{~d}$. All animals were treated with ampicillin, gentamicin, and prophylactic fluconazole for the duration of the study. All management protocols were as previously described (10). Amniotic fluid, fetal membranes, deciduas, fetal lung fluid, serial tracheal aspirates, blood, lung, and brain were processed for culture and polymerase chain reaction for Ureaplasma.

Archived lung specimens. Archived necropsy frozen lung and paraffinembedded sections from nine antenatal UU-infected animals were provided by the Baboon BPD Resource Center. Additional archived samples from 125-d $(n=7)$ and 140-d $(n=7)$ GC euthanized at delivery and noninfected, 125-d infants maintained $14 \mathrm{~d}$ postpartum with $\mathrm{O}_{2}$ as needed (p.r.n.) (125 d: 14 d p.r.n. $\mathrm{O}_{2} ; n=6$ ) were also provided for comparison studies. The control animals also served as controls for established projects within the BPD research program, which did not allow for sham intrauterine amniocentesis in these animals. The archived control samples were not from the same time period as the Ureaplasma experimental group, but the control animals were managed with the same ventilatory, cardiovascular, and nutritional protocols as those used for the experimental group except for the antenatal infection. At necropsy, the right middle lobe was air inflated and snap frozen in liquid nitrogen for later homogenization. The right lower lobe was removed, weighed, and intrabronchially fixed with phosphate-buffered $4 \%$ paraformaldehyde and $0.1 \%$ glutaraldehyde at $20 \mathrm{~cm} \mathrm{H}_{2} \mathrm{O}$ constant pressure for $24 \mathrm{~h}$. The lobe was cut into three serial, equally spaced horizontal tissue sections. These specimens were dehydrated in alcohol, embedded in paraffin, and cut at $4 \mu \mathrm{m}$ and mounted on slides for histologic studies.

Trichrome stain for collagen. Lung sections were processed for Masson's trichrome stain, a specific histochemical stain for collagen, using the Accustain Trichrome Stain Kit (Sigma Chemical Co., St. Louis, MO). Fibrosis was evaluated subjectively as previously described (4).

$\boldsymbol{\alpha}$-SMA. Immunohistochemical studies were performed to detect $\alpha$-SMA, a marker of myofibroblasts and smooth muscle. Sections were deparaffinized, and endogenous peroxidase activity was blocked by incubation with $3 \% \mathrm{H}_{2} \mathrm{O}_{2}$ in $100 \%$ methanol. For antigen retrieval, sections were treated in a microwave oven in the presence of saturated lead II thiocyanate for $10 \mathrm{~min}$. Section were incubated with ready to use monoclonal anti- $\alpha$-SMA antibody (Biogenex, San Ramon, CA) for $30 \mathrm{~min}$ at room temperature and processed using the Biogenex Super Sensitive Detection System(Biogenex) according to the manufacturer's protocol. Slides were counterstained with hematoxylin.

$\boldsymbol{T G F} \boldsymbol{\beta}_{1}$. For TGF $\beta_{1}$ immunohistochemical analysis, we used a polyclonal rabbit antibody raised against a peptide at the carboxy terminus of the precursor form of human TGF $\beta_{1}$ that does not cross-react with other TGF $\beta$ isoforms [anti-TGF $\beta_{1}$ (V) antibody, Santa Cruz, CA]. Lung sections were rehydrated, endogenous peroxidase activity was blocked, and the tissues treated in a microwave oven in the presence of sodium citrate $(10 \mathrm{mM}, \mathrm{pH}$ 6.0) for $10 \mathrm{~min}$. After blocking with $2 \%$ normal goat serum in phosphatebuffered saline (PBS) for 30 min, anti-TGF $\beta_{1}(\mathrm{~V})$ antibody was added at 1:50 dilution and incubated overnight at $4{ }^{\circ} \mathrm{C}$. After rinsing with PBS, biotinylated goat anti-rabbit $\mathrm{IgG}$ was applied at 1:200 dilution for $30 \mathrm{~min}$ at room temperature. Tissues were then treated with avidin-biotin complex for $30 \mathrm{~min}$ at room temperature. Color was developed by exposure to 3,3'diaminobenzidine (DAB) tetrahydrochloride for $2 \mathrm{~min}$, and tissue sections were counterstained with hematoxylin. Autopsy lung tissue from a human BPD infant was processed as a positive control. Negative controls were sections processed in the absence of primary antibody.

Lung homogenate ELISA. Aliquots of frozen lung specimens were homogenized in $1 \mathrm{~mL}$ of $150 \mathrm{mM} \mathrm{NaCl}, 2 \mathrm{mM}$ Tris, $\mathrm{pH} 7.5,0.5 \%$ Triton $\mathrm{X}$ containing protease inhibitors (Complete Mini tablets; Roche Molecular Biochemicals, Indianapolis, IN). Cytokines [TNF- $\alpha$, IL- $1 \beta$, active TGF $\beta_{1}$, OSM, IFN $\gamma$, IL-10] and chemokines (MCP-1) were measured in duplicate in the lung homogenate samples using standard two-antibody ELISA with commercial antibody pairs and recombinant standards (Endogen, Boston, MA) as previously described (20). Active TGF $\beta_{1}$ was measured without acid activation of samples. A curve was fit to the standards using a computer program (Softpro, Molecular Devices), and cytokine concentrations from each sample were calculated from the standard curve and normalized for lung homogenate protein measured by the Bradford method using Bio-Rad protein assay reagent (Hercules, CA).

Lung homogenate Smad immunoblotting. Lung homogenate extracts of two animals per group were separated by sodium dodecyl sulfate/ polyacrylamide gel electrophoreses (SDS/PAGE) under reducing conditions. Proteins were transferred to a nitrocellulose membrane. Immunoblotting was performed using goat anti-Smad2, -Smad3, or -Smad7 antibodies (Santa Cruz Biotechnology, Santa Cruz, CA) followed by incubation with anti-goat horseradish peroxidase-conjugated secondary antibody and detected by chemiluminescence (21). Gel images were collected using a Storm densitometer and band densities were analyzed with ImageQuant software (Molecular Dynam- 
ics). Data were expressed as the ratio of Smad2/Smad7 and Smad3/Smad7 for each sample.

Data analysis. Lung homogenate cytokine data are expressed as pg/mg homogenate protein. Statistical analysis was performed using the Statview II statistical software package (Abacus Concepts, Inc., Berkeley, CA). Differences among the groups were compared by analysis of variance. A $p$ value $<0.05$ was required for significance.

\section{RESULTS}

Increased interstitial fibrosis in UU-infected animals. Amniotic fluid and tracheal aspirates from all the antenatal UUinfected baboons were UU-culture positive at birth, but five animals had cleared their infection from the airway (UU-) and four remained infected with UU CFU counts $>4 \times 10^{3}$ at necropsy (UU+) (10). In the present study, trichrome staining revealed mild to moderate focal fibrosis in lung sections from the UU - animals, but more extensive fibrosis with thickened interstitium in the persistent UU+ animals (Fig. 1D). There was undetectable or minimal collagen staining in the GCs and none to mild focal fibrosis in the noninfected, p.r.n. $\mathrm{O}_{2}$ controls (Fig. 1A-C).

Increased number of myofibroblasts in UU-infected 125-d animals. We examined lung tissues for the presence of $\alpha$-SMA-expressing myofibroblasts using a monoclonal antihuman antibody directed against $\alpha$-SMA. In GCs (Fig. $2 A$ and $B)$, there was immunostaining of blood vessels, bronchial walls, and septal tips as expected. There was focal $\alpha$-SMA immunostaining in the interstitium of noninfected p.r.n. $\mathrm{O}_{2}$ controls (Fig. 2C), but more extensive, intense staining for $\alpha$-SMA in thickened interstitium of the UU-infected lung (Fig. $2 D$, arrow). Immunostaining was greater in lung sections from persistent UU+ animals than in sections from lungs of animals that were culture negative at necropsy (UU-).

TGF $\beta_{1}$ immunostaining of pulmonary macrophages in $\boldsymbol{U U}$-infected animals. In GCs, there was limited $\mathrm{TGF} \beta_{1}$ immunostaining to scattered airway cells, most likely amniotic squamous cells (Fig. $3 A$ and $B$ ). In lung specimens from

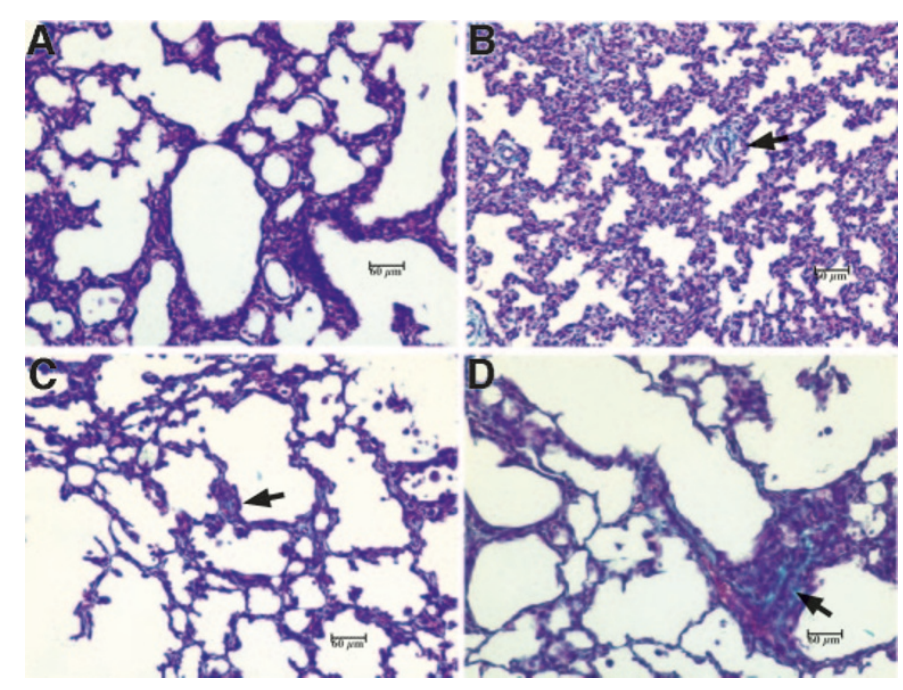

Figure 1. Collagen staining is increased in lung tissue from antenatal UUinfected baboons. Lung sections were stained with trichrome stain. (A) 125-d GC; (B) 140-d GC; (C) 125-d 14 d p.r.n. $\mathrm{O}_{2}$; and $(D)$ 125-d 14 d p.r.n. $\mathrm{O}_{2}$ $\mathrm{UU}+$. The most marked fibrosis occurred in the UU-infected lung (arrow). Magnification $\times 200$.
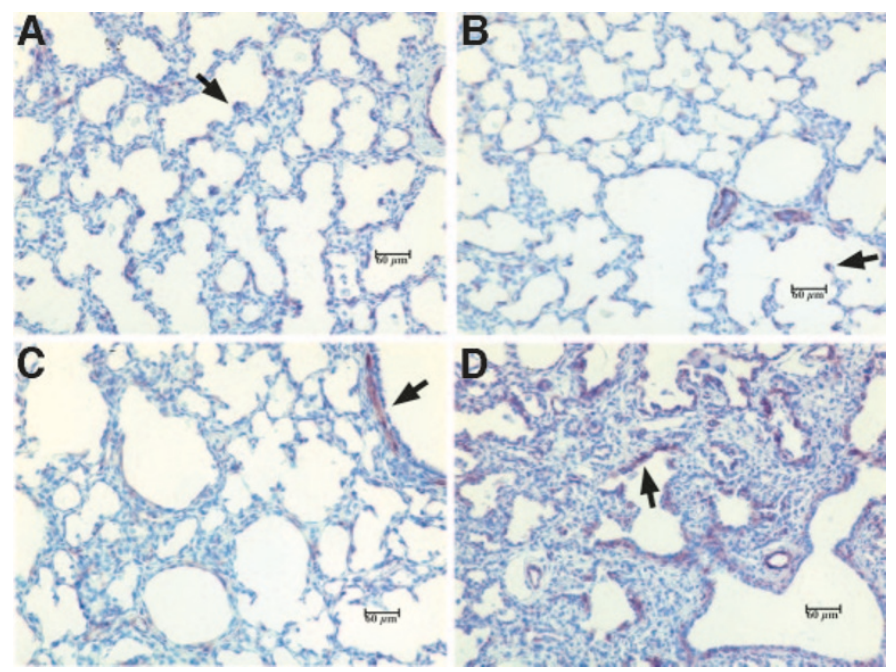

Figure 2. $\alpha$-SMA + cells are increased in lung tissue form antenatal UUinfected baboons. Lung sections were processed for immunohistochemical staining using a monoclonal anti-human antibody directed against $\alpha$-SMA. (A) 125-d GC; (B) 140-d GC; (C) 125-d 14 d p.r.n. $\mathrm{O}_{2}$; and (D) 125-d 14 d p.r.n. $\mathrm{O}_{2} \mathrm{UU}+$. Arrows indicate interstitial $\alpha$-SMA staining. Magnification $\times 200$.

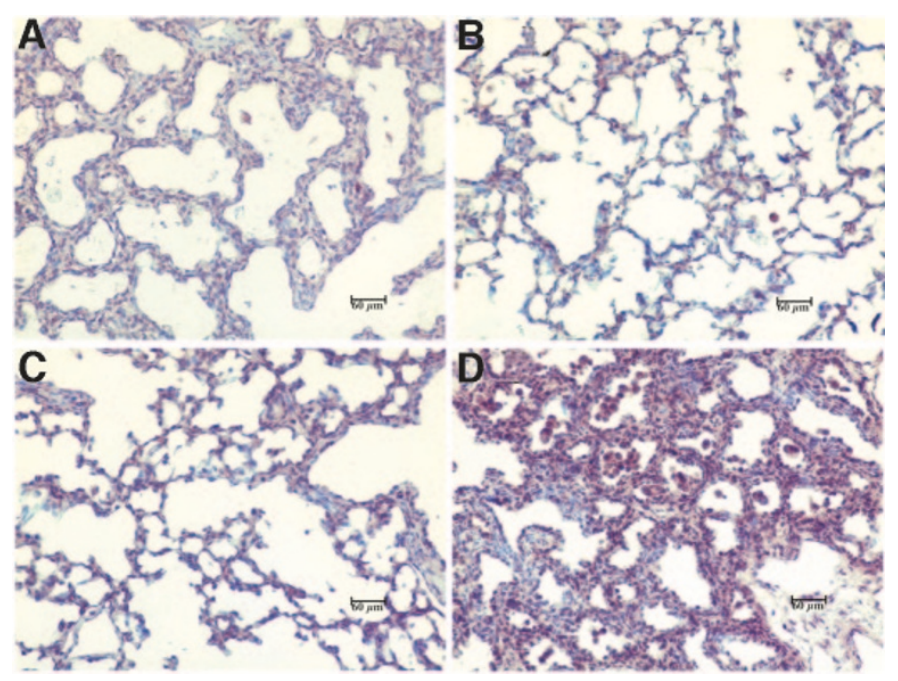

Figure 3. TGF $\beta_{1}$ immunostaining in lung specimens of antenatal UUexposed baboons is concentrated in focal aggregates of alveolar and interstitial macrophages. Lung sections were incubated with anti-TGF $\beta_{1}$ antibody, stained with diaminobenzidine and counterstained with hematoxylin. (A) 125-d GC; (B) 140-d GC; $(C)$ 125-d 14 d p.r.n. $\mathrm{O}_{2}$; and $(D)$ 125-d 14 d p.r.n. $\mathrm{O}_{2} \mathrm{UU}+$. Magnification $\times 200$.

noninfected p.r.n. $\mathrm{O}_{2}$ control, immunostaining was concentrated in small, focal aggregates of alveolar and interstitial macrophages (Fig. 3C). In Ureaplasma lung specimens, $\operatorname{TGF} \beta_{1}$ immunostaining was localized to large aggregates of alveolar macrophages and in areas of focal consolidation (Fig. 3D). These findings were more common in the UU+ than UU- animals.

Effect of antenatal UU infection and postnatal mechanical ventilation on lung cytokine/chemokine expression. Cytokines/chemokines were measured by ELISA in lung homogenates. There were no significant differences between 125 -d and 140-d GC lung homogenates in concentrations of any of the measured cytokines (Fig. $4 A-F$ ). The proinflammatory 

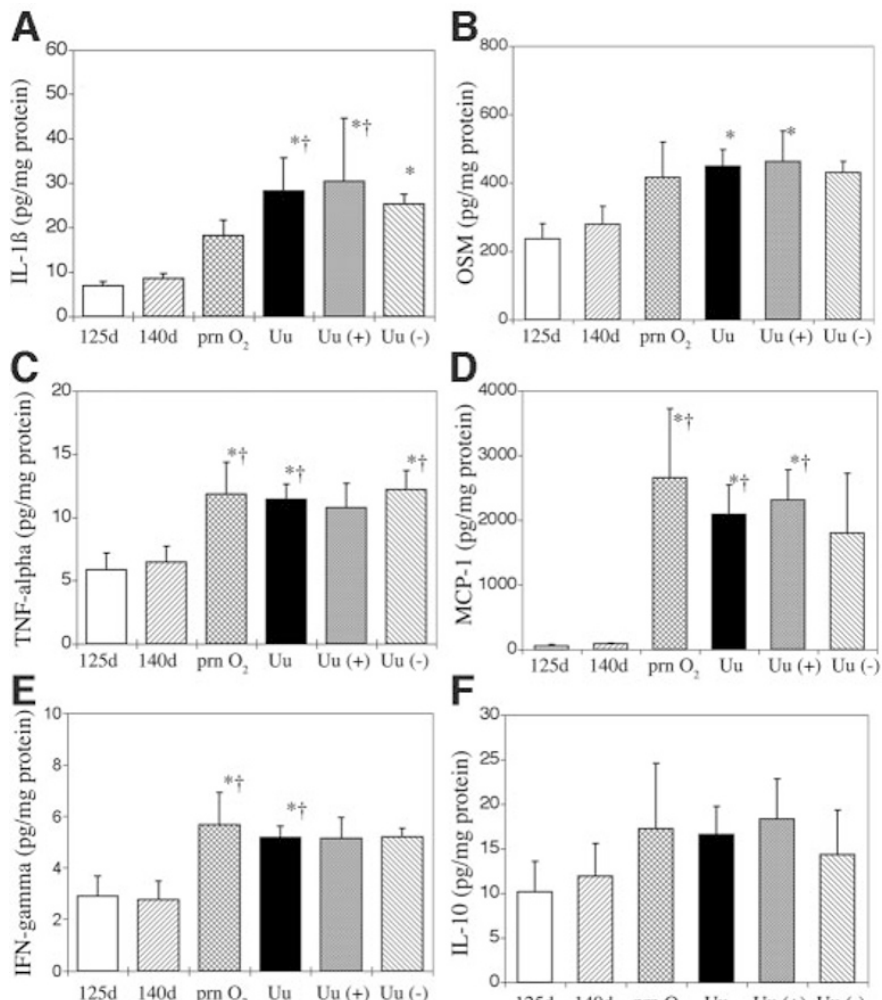

$F$

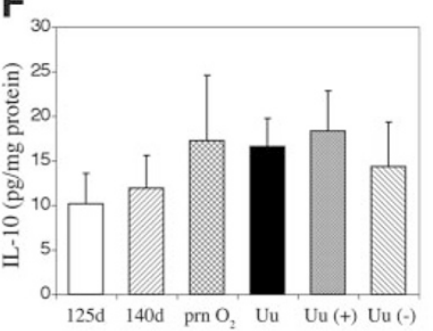

Figure 4. Comparison of cytokine concentrations in lung homogenates of gestational and ventilated controls and antenatal UU-infected baboons. Cytokines were measure by ELISA and expressed as the mean \pm SEM pg/mg lung homogenate protein ( $n=6$ each control group; $n=9 \mathrm{UU})$. The antenatal UU-infected group was further subdivided by culture status at necropsy (UU,$+ n=4$; UU-, $n=5$ ). * $p<0.05$ compared with 125 -d GCs; $\dagger p<0.05$ compared with 140-d GCs.

cytokine IL-1 $\beta$, and profibrotic cytokine OSM were significantly elevated four- and twofold, respectively, in the UUinfected animals compared with $125-\mathrm{d}$ GCs, but not in the noninfected ventilated controls (Fig. $4 A$ and $B$ ). The concentrations of these cytokines were higher in lung homogenates from animals that remained Ureaplasma culture positive at necropsy than in lung homogenates from animals that had cleared the infection. In contrast, $\mathrm{TNF} \alpha, \mathrm{MCP}-1$ and IFN $\gamma$ are increased two-, 40-, and twofold in both noninfected and UU-infected ventilated groups (Fig. $4 C-E$ ). There were no significant differences among the groups for IL-10 concentration (Fig. 4F).

TGF $\beta_{1}$ signaling in antenatal $U U$-infected animals. Active TGF $\beta_{1}$ and Smad proteins were measured in lung homogenates of a subset of each group due to limited tissue samples. After $14 \mathrm{~d}$ of ventilation, active TGF $\beta_{1}$ was increased in lung homogenates of UU-infected animals compared with gestational and ventilated controls (Fig. 5A). To determine whether antenatal Ureaplasma exposure and/or ventilation altered $\operatorname{TGF} \beta_{1}$ Smad signaling, we measured the relative concentrations of total Smad2 and Smad3 (TGF $\beta_{1}$ signaling agonists) and Smad7 (TGF $\beta_{1}$ signaling antagonist) by Western blot of lung homogenates. There was a trend toward increased ratios of Smad2/Smad7 $(p=0.37)$ and $\operatorname{Smad} 3 / \operatorname{Smad} 7(p=0.26)$ in UU-infected lung compared with gestational and ventilated
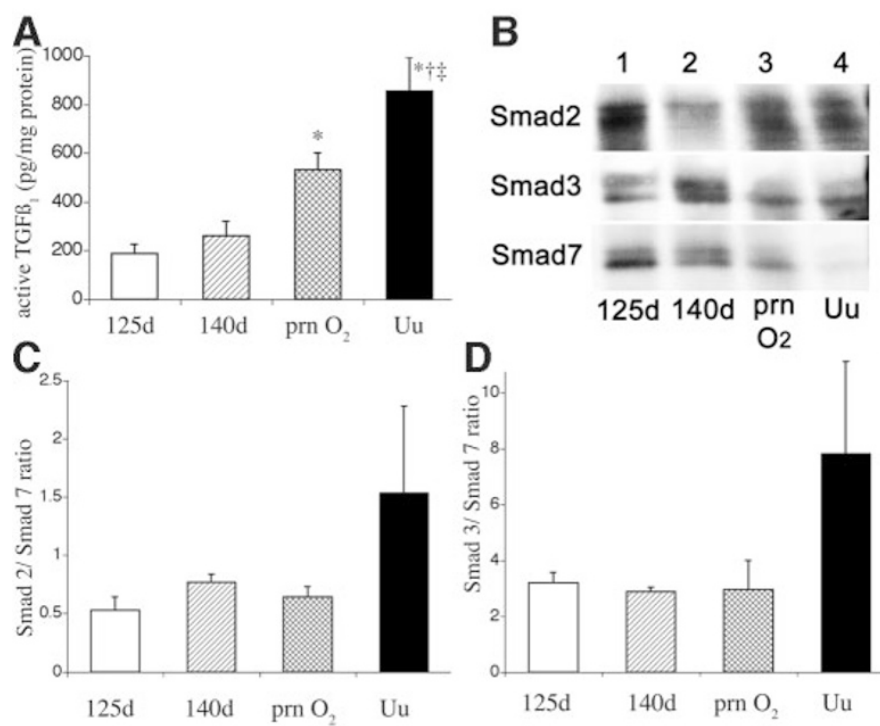

Figure 5. Active $\operatorname{TGF} \beta_{1}$ and ratios of Smad2/Smad7 and Smad3/Smad7 in lung homogenates of gestational and ventilated controls and antenatal UUinfected immature baboon. Lung homogenates from GC, noninfected, and UU-infected p.r.n. $\mathrm{O}_{2}$ groups $(n=3$ per group) were assayed for active $\mathrm{TGF} \beta_{1}$ by ELISA and expressed as mean \pm SEM $\mathrm{pg} / \mathrm{mg}$ lung homogenate protein $(A)$. Aliquots of lung homogenates ( $n=2$ per group) were separated by SDS/PAGE and immunoblotting performed with goat anti-Smad2, -Smad3, or -Smad7 antibodies $(B)$. The amount of immunoreactive protein was quantitated by densitometry. Data are expressed as the mean \pm SD ratio of the densitometry measurements of $\operatorname{Smad} 2 / \mathrm{Smad} 7(C)$ or $\mathrm{Smad} 3 / \mathrm{Smad} 7$ (D). $* p<0.05$ compared with 125 -d GC; $\dagger p<0.05$ compared with 140 -d GCs; $\ddagger p<0.05$ compared with 14 d p.r.n. $\mathrm{O}_{2}$.

controls, consistent with up-regulation of $\operatorname{TGF} \beta_{1}$ signaling (Fig. 5B-D).

\section{DISCUSSION}

In the initial study of antenatal Ureaplasma in the immature baboon model, early and sustained lung inflammation was demonstrated by significant increases in white blood cells and IL-8 in amniotic fluid, fetal lung liquid and serial tracheal aspirates (10). Compared with noninfected, p.r.n. $\mathrm{O}_{2}$ controls, persistently Ureaplasma culture-positive animals had significantly higher $\mathrm{FiO}_{2}$ requirements, airway pressures, oxygenation index, and ventilation efficiency index between 48 and $240 \mathrm{~h}$. When compared with control specimens, lung histopathology in both the culture-positive and culture-negative Ureaplasma groups showed bronchiolitis and interstitial pneumonitis of greater severity and increased numbers of alveolar macrophages, suggesting that despite apparent clearance of Ureaplasma in some animals, there remained persistent abnormalities of the pulmonary immune response. The current study extends these observations to show that inflammation initiated in utero by Ureaplasma exposure contributes to prolonged inflammation, early fibrosis, and altered TGF $\beta_{1}$ signaling.

Prolonged expression of inflammatory cytokines contributes to fibrosis and altered developmental signaling. IL- $1 \beta$ and OSM were specifically elevated in lung homogenates of Ureaplasma-infected animals. The association of the proinflammatory cytokine IL- $1 \beta$ with BPD and with Ureaplasma re- 
spiratory colonization of human preterm infants has been previously described $(5,22)$, but OSM has not been previously studied in the newborn lung. Transient overexpression of IL- $1 \beta$ mediates lung fibrosis proportionate to TGF $\beta_{1}$ levels generated in these models (23), providing a mechanism for inflammation-mediated fibrosis. OSM, a member of the IL-6 cytokine family, is expressed by alveolar epithelial cells and alveolar macrophages (24). OSM stimulates human lung fibroblast proliferation and collagen production and inhibits fibroblast apoptosis in vitro (25). Transient overexpression of OSM in murine lung by adenoviral transfer stimulates an influx of neutrophils and mononuclear cells and collagen deposition (26). OSM may regulate extracellular matrix by stimulating tissue inhibitor of metalloproteinases 1 (27) and plasminogen activator (28). The present study is the first to implicate OSM in the pathogenesis of BPD.

In the present study, lung lavage concentrations of the anti-inflammatory cytokine IL-10 were not statistically different among the groups. This is in agreement with previous studies demonstrating low expression of IL-10 in the human preterm lung (13) and the immature baboon model (29) and supports the contention that BPD is the result of an imbalance of pro- and anti-inflammatory mediators (30). IL-10 suppresses the innate immune response by down-regulating $\mathrm{TNF} \alpha$, IL-1 $\beta$, and IL-8 expression (31). IL-10 may also be antifibrotic. Pretreatment with liposomes containing a human IL-10 expression vector inhibited bleomycin-induced fibrosis in mice, in part, by suppressing TNF $\alpha$ expression (32). IL-10 directly reduced constitutive and $\operatorname{TGF} \beta_{1}$-stimulated type I collagen mRNA expression by scleroderma and normal dermal fibroblasts (33). IL-10 induced gene expression of decorin, a TGF $\beta$ antagonist in dermal fibroblasts (33). Conditioned medium from cultured normal lung fibroblasts, but not fibroblasts from fibrotic lungs, stimulated IL-10 release from monocytes, suggesting that fibrosis might contribute to the maintenance of chronic inflammation (34). We have previously demonstrated that Ureaplasma reduced endotoxinstimulated IL-10 release by preterm cord blood monocytes in vitro (35). We speculate that a reduced capacity to produce IL-10 in the injured preterm lung combined with further suppression of IL-10 by Ureaplasma infection might contribute to both chronic inflammation and fibrosis.

The Smad proteins are important intracellular mediators of TGF $\beta_{1}$ signaling. Changes in Smad protein expression have been implicated in fibrotic lung diseases $(21,36,37)$. In bleomycin-induced lung fibrosis in rats, there is a persistent increase in phosphorylation and nuclear accumulation of Smad2/Smad3 and progressive decrease of Smad7 (37). Smad3 deficiency (36) and Smad7 overexpression (38) reduce bleomycin-induced lung fibrosis. Smad3 mediates TGF $\beta_{1^{-}}$ induced fibroblast proliferation, myofibroblast differentiation, and collagen accumulation (36). Constitutive and TGF $\beta$ induced expression of Smad7 was selectively depressed and Smad3 expression increased in cultured fibroblasts from subjects with scleroderma, suggesting that alterations in the Smad pathway contribute to the pathogenesis of TGF $\beta$-mediated fibrosis in this disease (21). Data in the current study indicate that antenatal Ureaplasma exposure contributes to an imbal- ance of $\mathrm{Smad} 2 / \mathrm{Smad} 3$ and the inhibitory Smad7 that results in persistent activation of $\operatorname{TGF} \beta_{1}$ and altered developmental signaling. In support of this contention, active TGF $\beta_{1}$ in lung lavage measured by ELISA was increased in Ureaplasmainfected lung. The Smad proteins are potential novel targets to prevent or ameliorate excessive TGF $\beta$ signaling during injury of the preterm lung.

There are a number of limitations of the present study. First, the duration of antenatal exposure was relatively brief and may not be consistent with actual exposure in the human situation in which intrauterine colonization may be present for weeks (39). In fetal sheep exposed to intra-amniotic Ureaplasma for periods up to $10 \mathrm{wk}$, long-term, but not short-term, exposure was associated with improvement in lung function, poor fetal growth, fetal acidemia, and evidence of fetal pulmonary inflammation (40). Second, control animals were not exposed to sham amniocentesis, allowing for the possibility that procedure-related stress may have contributed to changes observed in the UU-infected animals. Third, the controls were not concurrent with the experimental animals, but all care protocols were the same. Fourth, indices of lung inflammation and fibrosis were obtained at a single time point. Whether the early fibrosis noted at $2 \mathrm{wk}$ of age persists or resolves over time in the antenatal UU-infected preterm baboon lung is unknown. In autopsy lung samples from human infants dying with Ureaplasma infection, myofibroblast accumulation and collagen and elastin deposition were evident up to $6 \mathrm{wk}$ postnatal age $(4,14)$. The observation that abnormalities persist despite clearance of the organism suggest that therapeutic interventions solely targeting organism eradication may be insufficient to prevent the infection-related sequelae. The primate model of antenatal Ureaplasma infection will be ideal for future studies to investigate the effects of a more prolonged intrauterine exposure and to assess the benefit of potential therapeutic interventions.

\section{REFERENCES}

1. Jobe AH, Bancalari E 2001Bronchopulmonary dysplasia. Am J Respir Crit Care Med 163:1723-1729

2. Yoon BH, Chang JW, Romero R 1998Isolation of Ureaplasma urealyticum from the amniotic cavity and adverse outcome in preterm labor. Obstet Gynecol 92:77-82

3. Waites KB, Katz B, Schelonka RL 2005Mycoplasmas and ureaplasmas as neonatal pathogens. Clin Microbiol Rev 18:757-789

4. Viscardi RM, Manimtim WM, Sun CC, Duffy L, Cassell GH 2002Lung pathology in premature infants with Ureaplasma urealyticum infection. Pediatr Dev Pathol 5:141-150

5. Patterson AM, Taciak V, Lovchik J, Fox RE, Campbell AB, Viscardi RM 1998Ureaplasma urealyticum respiratory tract colonization is associated with an increase in IL- $1 \beta$ and TNF- $\alpha$ relative to IL- 6 in tracheal aspirates of preterm infants. Pediatr Infect Dis J 17:321-328

6. Baier RJ, Loggins J, Kruger TE 2001Monocyte chemoattractant protein-1 and interleukin-8 are increased in bronchopulmonary dysplasia: relation to isolation of Ureaplasma urealyticum. J Investig Med 49:362-369

7. Walsh WF, Butler J, Coalson J, Hensley D, Cassell GH, deLemos RA 1993A primate model of Ureaplasma urealyticum infection in the premature infant with hyaline membrane disease. Clin Infect Dis 17:S158-S162

8. Rudd PT, Cassell GH, Waites KB, Davis JK, Duffy LB 1989 Ureaplasma urealyticum pneumonia: experimental production and demonstration of age-related susceptibility. Infect Immun 57:918-925

9. Viscardi RM, Kaplan J, Lovchik JC, He JR, Hester L, Rao S, Hasday JD 2002Characterization of a murine model of Ureaplasma urealyticum pneumonia. Infect Immun 70:5721-5729

10. Yoder BA, Coalson JJ, Winter VT, Siler-Khodr T, Duffy LB, Cassell GH 2003Effects of antenatal colonization with Ureaplasma urealyticum on pulmonary disease in the immature baboon. Pediatr Res 54:797-807

11. Warburton D, Tefft D, Mailleux A, Bellusci S, Thiery JP, Zhao J, Buckley S, Shi W, Driscoll B 2001Do lung remodeling, repair, and regeneration recapitulate respiratory ontogeny? Am J Respir Crit Care Med 164:S59-S62 
12. Toti P, Buonocore G, Tanganelli P, Catella AM, Palmeri ML, Vatti R, Seemayer TA 1997Bronchopulmonary dysplasia of the premature baby: an immunohistochemical study. Pediatr Pulmonol 24:22-28

13. Jonsson B, Li YH, Noack G, Brauner A, Tullus K 2000Downregulatory cytokines in tracheobronchial aspirate fluid from infants with chronic lung disease of prematurity. Acta Paediatr 89:1375-1380

14. Viscardi RM, Manimtim W, He JR, Hasday JD, Sun CC, Joyce B, Pierce RA 2006Disordered pulmonary myofibroblast distribution and elastin expression in preterm infants with Ureaplasma urealyticum pneumonitis. Pediatr Dev Pathol (in press)

15. Zeng X, Gray M, Stahlman MT, Whitsett JA 2001TGF-beta1 perturbs vascular development and inhibits epithelial differentiation in fetal lung in vivo. Dev Dyn 221:289-301

16. Vicencio AG, Lee CG, Cho SJ, Eickelberg O, Chuu Y, Haddad GG, Elias JA 2004Conditional overexpression of bioactive transforming growth factor-beta1 in neonatal mouse lung: a new model for bronchopulmonary dysplasia? Am J Respir Cell Mol Biol 31:650-656

17. Gauldie J, Galt T, Bonniaud P, Robbins C, Kelly M, Warburton D 2003Transfer of the active form of transforming growth factor-beta 1 gene to newborn rat lung induces changes consistent with bronchopulmonary dysplasia. Am J Pathol 163:2575-2584

18. Zhao J, Lee M, Smith S, Warburton D 1998Abrogation of Smad3 and Smad2 or of Smad4 gene expression positively regulates murine embryonic lung branching morphogenesis in culture. Dev Biol 194:182-195

19. Zhao J, Crowe DL, Castillo C, Wuenschell C, Chai Y, Warburton D 2000Smad7 is a TGF-beta-inducible attenuator of Smad2/3-mediated inhibition of embryonic lung morphogenesis. Mech Dev 93:71-81

20. Jiang Q, Cross AS, Singh IS, Chen TT, Viscardi RM, Hasday JD 2000Febrile core temperature is essential for optimal host defense in bacterial peritonitis. Infect Immun 68:1265-1270

21. Dong C, Zhu S, Wang T, Yoon W, Li Z, Alvarez RJ, ten Dijke P, White B, Wigley RM, Goldschmidt-Clermont PJ 2002Deficient Smad7 expression: a putative molecular defect in scleroderma. Proc Natl Acad Sci U S A 99:3908-3913

22. Rindfleisch MS, Hasday JD, Taciak V, Broderick K, Viscardi RM 1996Potential role of interleukin-1 in the development of bronchopulmonary dysplasia. J Interferon Cytokine Res 16:365-373

23. Kolb M, Margetts P, Anthony D, Pitossi F, Gauldie J 2001Transient expression of IL-1 $\beta$ induces acute lung injury and chronic repair leading to pulmonary fibrosis. J Clin Invest 107:1529-1536

24. Kodelja V, Muller C, Politz O, Hakij N, Orfanos CE, Goerdt S 1998Alternative macrophage activation-associated CC-chemokine-1, a novel structural homologue of macrophage inflammatory protein-1 alpha with a Th2-associated expression pattern. J Immunol 160:1411-1418

25. Scaffidi AK, Mutsaers SE, Moodley YP, McAnulty RJ, Laurent GJ, Thompson PJ, Knight DA 2002Oncostatin M stimulates proliferation, induces collagen production and inhibits apoptosis of human lung fibroblasts. Br J Pharmacol 136:793-801

26. Richards CD, Kerr C, Tong L, Langdon C 2002Modulation of extracellular matrix using adenovirus vectors. Biochem Soc Trans 30:107-111
27. Richards CD, Kerr C, Tanaka M, Hara T, Miyajima A, Pennica D, Botelho F, Langdon CM 1997Regulation of tissue inhibitor of metalloproteinase-1 in fibroblasts and acute phase proteins in hepatocytes in vitro by mouse oncostatin M, cardiotrophin-1, and IL-6. J Immunol 159:2431-2437

28. Strand K, Murray J, Aziz S, Ishida A, Rahman S, Patel Y, Cardona C, Hammond WP, Savidge G, Wijelath ES 2000Induction of the urokinase plasminogen activator system by oncostatin $\mathrm{M}$ promotes endothelial migration. J Cell Biochem 79:239-248

29. Coalson JJ, Winter VT, Siler-Khodr T, Yoder BA 1999Neonatal chronic lung disease in extremely immature baboons. Am J Respir Crit Care Med 160:1333-1346

30. Jobe AH, Ikegami M 2001Antenatal infection/inflammation and postnatal lung maturation and injury. Respir Res 2:27-32

31. Mosmann TR 1994Properties and functions of interleukin-10. Adv Immunol $56: 1-26$

32. Arai T, Abe K, Matsuoka H, Yoshida M, Mori M, Goya S, Kida H, Nishino K, Osaki T, Tachibana I, Kaneda Y, Hayashi S 2000Introduction of the interleukin-10 gene into mice inhibited bleomycin-induced lung injury in vivo. Am J Physiol Lung Cell Mol Physiol 278:L914-L922

33. Yamamoto T, Eckes B, Krieg T 2001Effect of interleukin-10 on the gene expression of type I collagen, fibronectin, and decorin in human skin fibroblasts: differential regulation by transforming growth factor-beta and monocyte chemoattractant protein-1. Biochem Biophys Res Commun 281:200-205

34. Vancheri C, Mastruzzo C, Tomaselli V, Sortino MA, D'Amico L, Bellistri G, Pistorio MP, Salinaro ET, Palermo F, Mistretta A, Crimi N 2001Normal human lung fibroblasts differently modulate interleukin-10 and interleukin-12 production by monocytes: implications for an altered immune response in pulmonary chronic inflammation. Am J Respir Cell Mol Biol 25:592-599

35. Manimtim WM, Hasday JD, Hester L, Fairchild KD, Lovchik JC, Viscardi RM 2001 Ureaplasma urealyticum modulates endotoxin-induced cytokine release by human monocytes derived from preterm and term newborns and adults. Infect Immun 69:3906-3915

36. Zhao J, Shi W, Wang YL, Chen H, Bringas P Jr, Datto MB, Frederick JP, Wang XF, Warburton D 2002Smad3 deficiency attenuates bleomycin-induced pulmonary fibrosis in mice. Am J Physiol Lung Cell Mol Physiol 282:L585-L593

37. Venkatesan N, Pini L, Ludwig MS 2004Changes in Smad expression and subcellular localization in bleomycin-induced pulmonary fibrosis. Am J Physiol Lung Cell Mol Physiol 287:L1342-L1347

38. Nakao A, Fujii M, Matsumura R, Kumano K, Saito Y, Miyazono K, Iwamoto 1999Transient gene transfer and expression of Smad7 prevents bleomycin-induced lung fibrosis in mice. J Clin Invest 104:5-11

39. Cassell GH, Davis RO, Waites KB, Brown MB, Marriott PA, Stagno S, Davis JK 1983Isolation of Mycoplasma hominis and Ureaplasma urealyticum from amniotic fluid at 16-20 weeks of gestation: potential effect on outcome of pregnancy. Sex Transm Dis 10:294-302

40. Moss TJ, Nitsos I, Ikegami M, Jobe AH, Newnham JP 2005Experimental intrauterine Ureaplasma infection in sheep. Am J Obstet Gynecol 192:1179-1186 